\title{
Aerodynamic Resistance and Penman-Monteith Evapotranspiration over a Seasonally Two-Layered Canopy in Semiarid Central Australia
}

\author{
JAMES CLEVERLY \\ Plant Functional Biology and Climate Change Cluster, School of the Environment, and Australian Supersite Network and OzFlux, \\ Terrestrial Ecosystem Research Network, University of Technology, Sydney, Broadway, New South Wales, Australia \\ Chao Chen, Nicolas Boulain, Randol Villalobos-Vega, Ralph Faux, Nicole Grant, \\ AND QIANG YU
}

Plant Functional Biology and Climate Change Cluster, School of the Environment, University of Technology, Sydney, Broadway, New South Wales, Australia

\section{DEREK EAMUS}

Plant Functional Biology and Climate Change Cluster, School of the Environment, and Australian Supersite Network and OzFlux, Terrestrial Ecosystem Research Network, and National Centre for Groundwater Research and Training, University of Technology, Sydney, Broadway, New South Wales, Australia

(Manuscript received 6 May 2013, in final form 29 July 2013)

\begin{abstract}
Accurate prediction of evapotranspiration $E$ depends upon representative characterization of meteorological conditions in the boundary layer. Drag and bulk transfer coefficient schemes for estimating aerodynamic resistance to vapor transfer were compared over a semiarid natural woodland ecosystem in central Australia. Aerodynamic resistance was overestimated from the drag coefficient, resulting in limited $E$ at intermediate values of vapor pressure deficit. Large vertical humidity gradients were present during the summer, causing divergence between momentum and vapor transport within and above the canopy surface. Because of intermittency in growth of the summer-active, rain-dependent understory and physiological responses of the canopy, leaf resistance varied from less than $50 \mathrm{~s} \mathrm{~m}^{-1}$ to greater than $10^{6} \mathrm{~s} \mathrm{~m}^{-1}$, in which the particularly large values were obtained from inversion of drag coefficient resistance. Soil moisture limitations further contributed to divergence between actual and reference $E$. Unsurprisingly, inclusion of site-specific meteorological (e.g., vertical humidity gradients) and hydrological (e.g., soil moisture content) information improved the accuracy of predicting $E$ when applying Penman-Monteith analysis. These results apply regardless of canopy layering (i.e., even when the understory was not present) wherever atmospheric humidity gradients develop and are thus not restricted to two-layer canopies in semiarid regions.
\end{abstract}

\section{Introduction}

One-fifth of the global land area is arid or semiarid, where water scarcity can limit productivity in agricultural and native vegetation. Except where groundwater is present, evapotranspiration $E$ in arid regions is second only to precipitation $P$ as the largest component of the hydrometeorological cycle (Sheffield et al. 2010); thus,

Corresponding author address: James Cleverly, Plant Functional Biology and Climate Change Cluster, School of the Environment, University of Technology, Sydney, PO Box 123, Broadway, NSW 2007, Australia.

E-mail: james.cleverly@uts.edu.au accurate knowledge of $E$ is required for managing water resources (Er-Raki et al. 2010; Tabari et al. 2012). Australia is the driest permanently inhabited continent on Earth, with over $70 \%$ of the land surface characterized as (semi) arid (Eamus and Froend 2006), where the seasonality of moisture limitations exerts strong control over vegetation characteristics and $E$ (Hutley et al. 2005; O'Grady et al. 2009).

To provide a reference of $E\left(E_{0}\right)$, the Food and Agricultural Organization adopted standard parameterization of the Penman-Monteith (PM) model for a reference grass crop (FAO56; Allen et al. 1998). This mechanistic model incorporates plant physiological constraints (Monteith 1965) into Penman's original model that

DOI: $10.1175 / J H M-D-13-080.1$

(C) 2013 American Meteorological Society 
combines available energy $Q_{A}$ with atmospheric constraints (Penman 1948). FAO56 remains the most feasible and widely adopted method for predicting $E$ across the globe (Steduto et al. 2003). The importance of FAO56 as a tool in water resources management is unequalled because of its simplicity and intercomparability among various crop and ecosystem types (Lemeur and Zhang 1990).

With the growth of worldwide eddy covariance (EC) networks, FAO56's aerodynamic resistance and surface conductance $G_{S}$ terms can be evaluated by inverting the equation with measured values of actual $E$ (Reichstein et al. 2002; Wohlfahrt et al. 2009). Numerous computational methods are used to estimate aerodynamic resistance to momentum flux $r_{a m}$ as a function of the drag coefficient $C_{D}$, either directly (i.e., from the friction coefficient $u^{*}$ in moderately unstable conditions; Isaac et al. 2004) or inferentially from the logarithmic profile of wind speed $U$ above a surface (Allen et al. 1998; Brutsaert 1982). Likewise, aerodynamic resistance to vapor transfer $r_{a v}$ is determined either directly from surface-to-air gradients of specific humidity (i.e., the bulk transfer coefficient $C_{E}$; Brutsaert 1982; Stull 1988) or inferentially from $C_{D}$, in which case $r_{a v}$ and $r_{a m}$ are equivalent. While direct assessment of $r_{a v}$ is preferred because of the unambiguous relationship between $C_{E}$ and $r_{a v}$, measurements of vertical profiles in humidity are historically rare and $r_{a v}$ must be inferred from $C_{D}$ (Brutsaert 1982; Cleugh et al. 2004).

Errors in Penman-Monteith (PM) predictions have been observed at low to moderate values of $D$ (Whitley et al. 2009). Thus, we hypothesized that these errors are the result of differences between $r_{a v}$ (from $C_{E}$ ) and $r_{a m}$ (from $C_{D}$ ). This study compares $r_{a v}$ to $r_{a m}$ by inverting the PM equation at an OzFlux EC site in semiarid, central Australia (Cleverly 2011). To clarify variable designations, the generic subscript $x$ will represent $m$ for momentum or $v$ for vapor (e.g., $G_{S x}$ represents $G_{S m}$ when derived from $r_{a m}$ ). Likewise, subscripts $a$ and $S$ refer to aerodynamic and surface, respectively.

\section{Measurements and methods}

\section{a. Aerodynamic resistance to momentum and vapor transfer}

Application of $r_{a m}$ to vapor transport follows an inverse function of $U$ and $C_{D}$, which can be estimated from canopy structural characteristics (Allen et al. 1998; Stull 1988):

$$
r_{a m}=\left(U C_{D}\right)^{-1} \approx \frac{\ln \left[\left(z_{m}-z_{d}\right) / z_{0 m}\right] \ln \left[\left(z_{m}-z_{d}\right) / z_{0 v}\right]}{k^{2} U}
$$

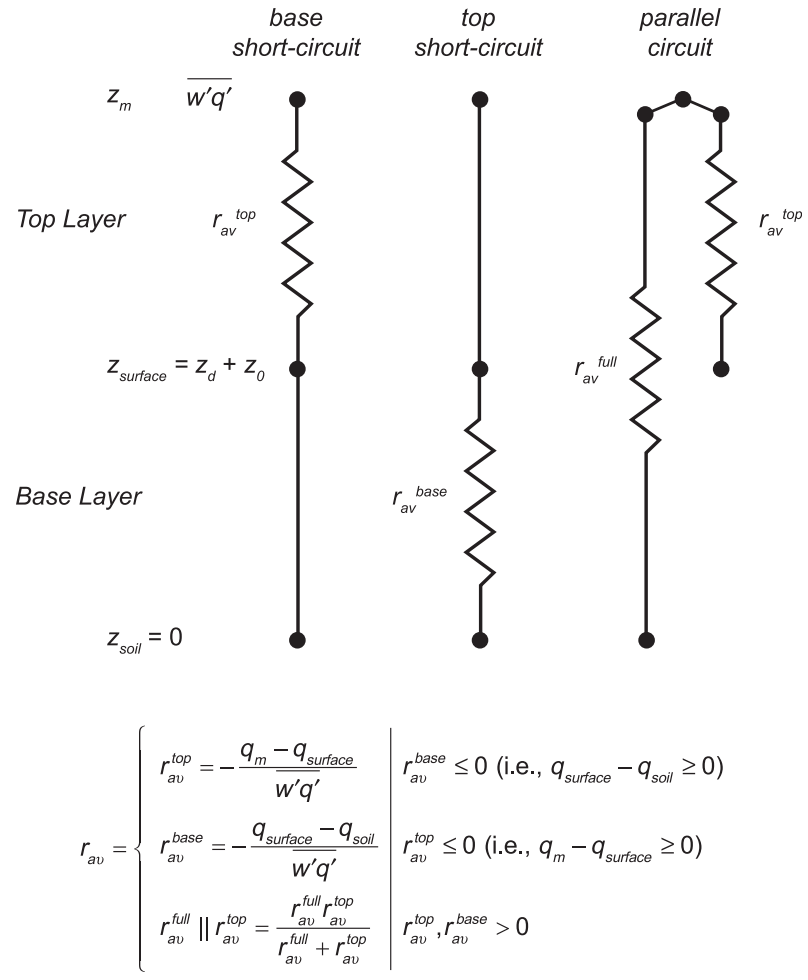

FIG. 1. Conditional three-circuit, two-layer aerodynamic resistance model. See text for variable descriptions.

where $k$ is von Kármán's constant $(0.41), z_{m}(\mathrm{~m})$ is the measurement height, $z_{d}(\mathrm{~m})$ is the displacement height $\left(2 / 3\right.$ of the canopy height $\left.z_{c}\right)$, and $z_{0 m}$ and $z_{0 v}(\mathrm{~m})$ are the roughness lengths for momentum and vapor, respectively. The logarithmic profile that underpins $r_{a m}$ is not applicable below the height $z_{d}$; thus, $r_{a m}$ was computed for a single layer representing the canopy surface.

Alternatively, aerodynamic resistance to vapor transport $r_{a v}$ was determined as a function of $U$ and $C_{E}$, which is determined as a function of $U$, kinematic vapor flux $\left(\overline{w^{\prime} q^{\prime}}\right)$, and the specific humidity $\left(q ; \mathrm{kg} \mathrm{kg}^{-1}\right)$ gradient between the surface and air $\left(q_{a}-q_{0}\right)$ (Brutsaert 1982; Stull 1988):

$$
r_{a v}=\left(U C_{E}\right)^{-1}=-\frac{q_{a}-q_{0}}{\overline{w^{\prime} q^{\prime}}} .
$$

Equation (2) is directly analogous to Ohm's law. Using profile measurements of $q, r_{a v}$ was solved during each half hour across two atmospheric layers during one of three scenarios (Fig. 1): 1) when $r_{a v}$ across the base layer was zero or undefined (base short circuit), 2) when $r_{a v}$ across the top layer was zero or undefined (top short circuit), or 3) when $r_{a v}$ across both layers was defined (parallel circuit). Layer boundaries were set to $z_{m}$, the effective canopy surface height $\left(z_{\text {surface }}=z_{d}+z_{0}\right)$, and 
a. Top layer

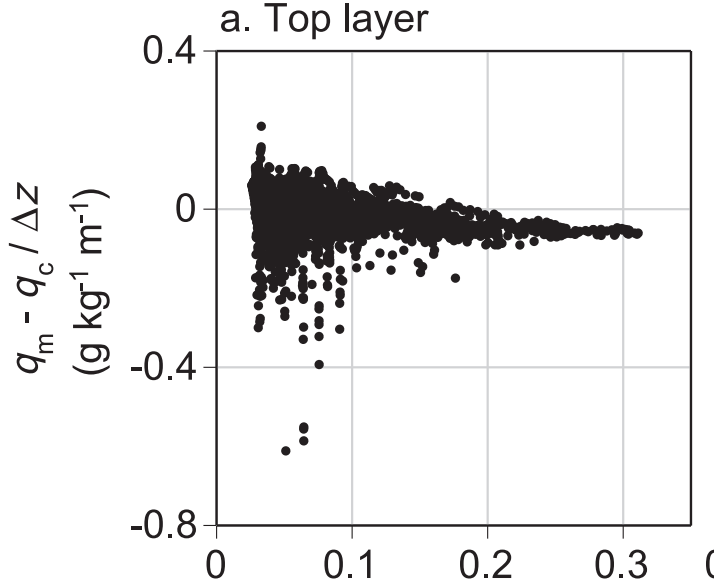

b. Base layer

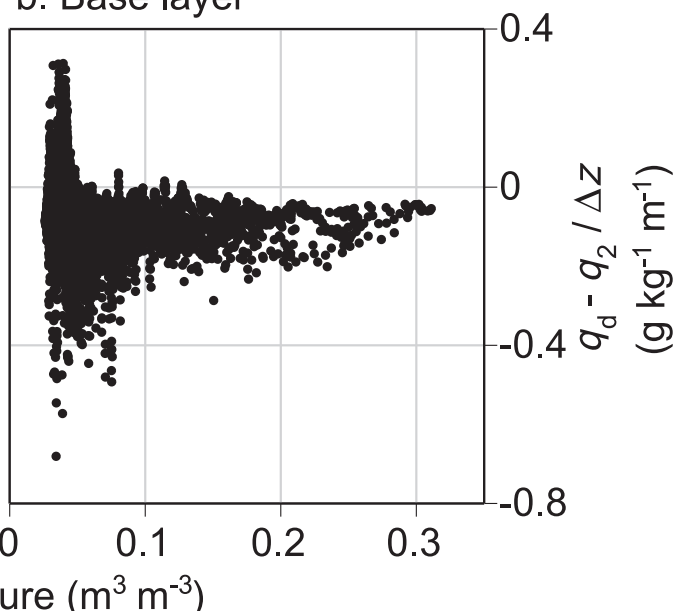

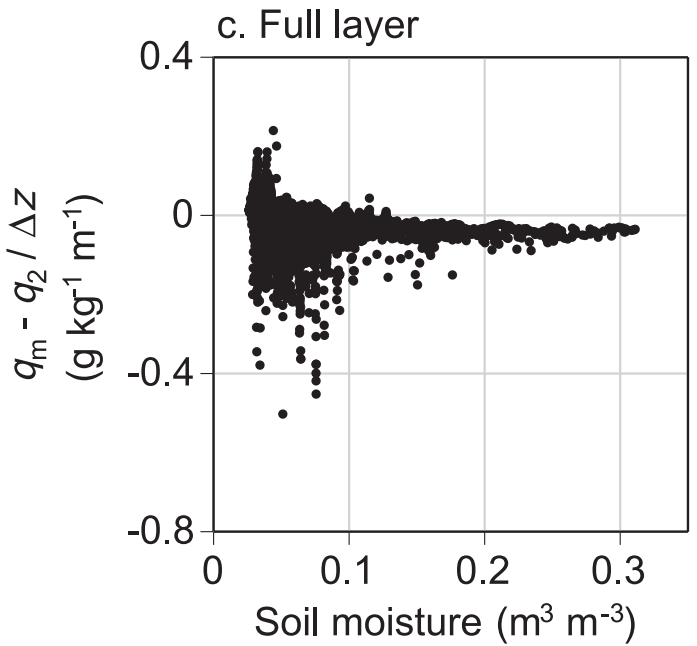

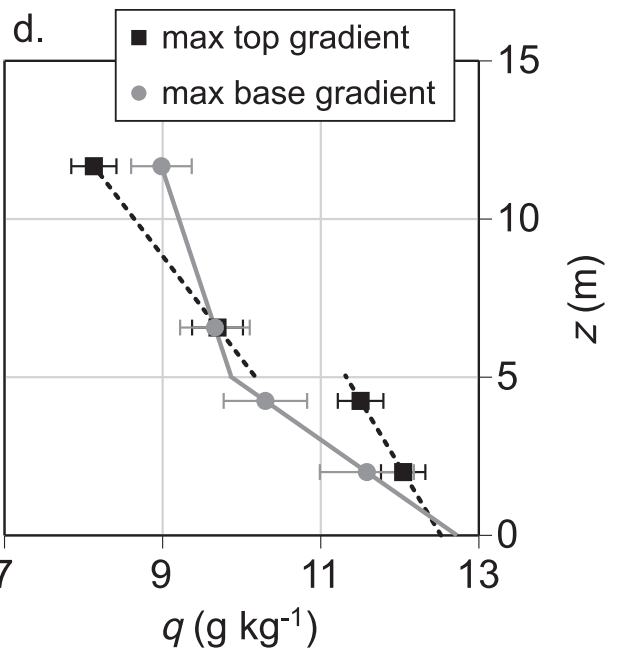

FIG. 2. Specific humidity $q$ profiles through the canopy and atmosphere, scaled by atmospheric layer thickness $\Delta z$. Subscripts represent measurement height. (a)-(c) The difference between $q$ measured at two heights (subscripts: $m$, measurement; $c$, canopy; 2, $2 \mathrm{~m}$ ). (d) Atmospheric $q$ profile ( \pm standard error) during the period of maximal gradients in the top layer (2100-2300 LST 22 Dec 2012; squares and broken line) and in the base layer (0130-0400 LST 5 Nov 2012; circles and solid line).

the soil surface ( $z_{\text {soil }}$; Fig. 1$)$. Measurement heights for the finite difference $q_{a}-q_{0}$ were set, for example, to $z_{m}$ and $z_{\text {surface }}$ in the top layer.

\section{b. Meteorology and eddy covariance}

$E$ and $\overline{w^{\prime} q^{\prime}}$ were measured using the eddy covariance method as fully described for this site in Eamus et al. (2013). Flux measurements were made at a height of $11.7 \mathrm{~m}\left(z_{m}\right)$ for vapor and momentum (CSAT3, Campbell Scientific Inc., Logan, Utah; LI7500, Li-Cor Biosciences, Lincoln, Nebraska) and $12.6 \mathrm{~m}$ for radiation (CNR1, Kipp \& Zonen, Delft, Netherlands). Surface soil moisture was measured across the top 10-cm depth (CS616, Campbell Scientific) and in profiles to 1-m depth
(CS605, Campbell Scientific; Cleverly et al. 2013). Soil porosity was $0.36 \pm 0.005 \mathrm{~m}^{3} \mathrm{~m}^{-3}$ above the variabledepth hardpan (Cleverly et al. 2013). Additionally, temperature and humidity measurements were made at heights of $11.7 \mathrm{~m}\left(z_{m}\right), 6.5 \mathrm{~m}\left(z_{c}\right), 4.25 \mathrm{~m}\left(z_{d}\right)$, and $2 \mathrm{~m}$ (HMP45C, Vaisala, Helsinki, Finland). Given the separation required to resolve differences between HMP45C measurements, $q_{0}$ and $q_{a}$ were obtained within each layer by linearly extrapolating paired measurements of $q$ with height. That is, $q_{0}$ was extrapolated from the slope $\left[\left(z_{m}-z_{c}\right) /\right.$ $\left.\left(q_{m}-q_{c}\right)\right]$ in the top layer and from the slope $\left[\left(z_{d}-2\right) /\right.$ $\left.\left(q_{d}-q_{2}\right)\right]$ in the base layer. All measurements were collected during the calendar year 2012 over a two-layer (canopy and soil plus intermittent understory) surface. 


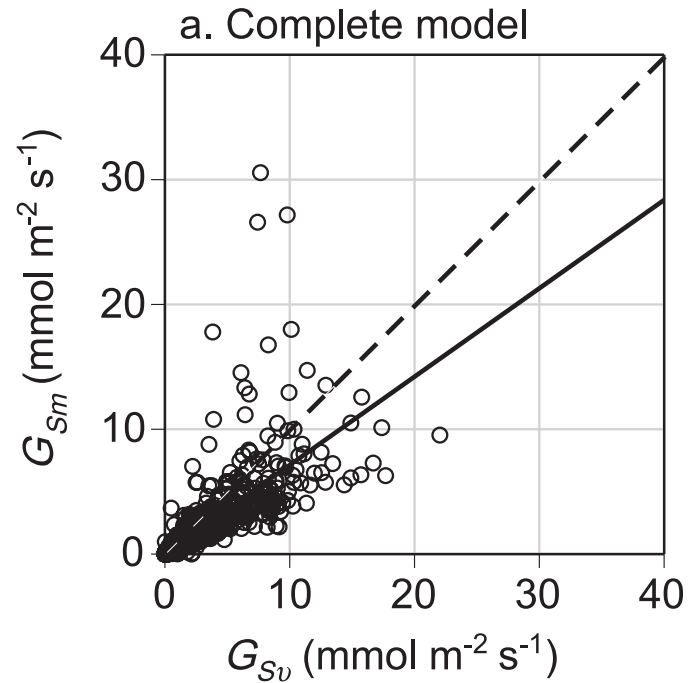

c. Component layers

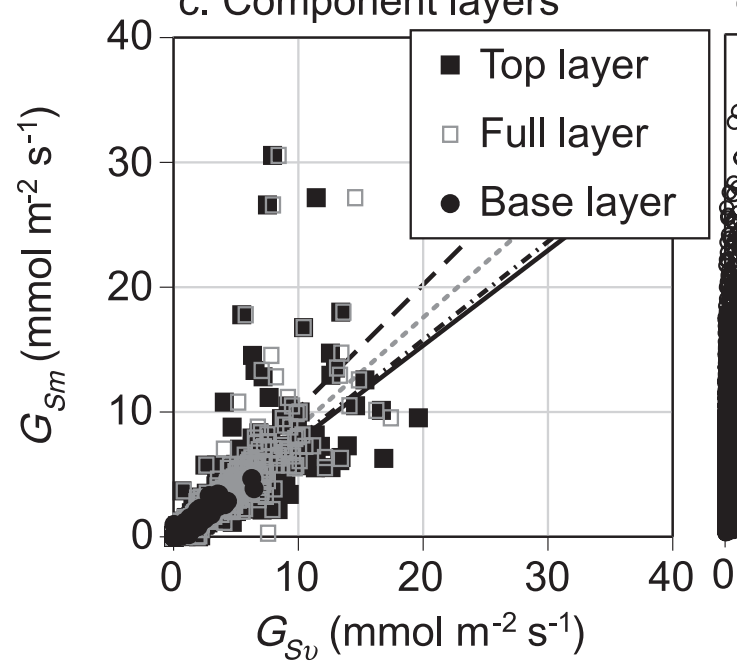

b. Daily

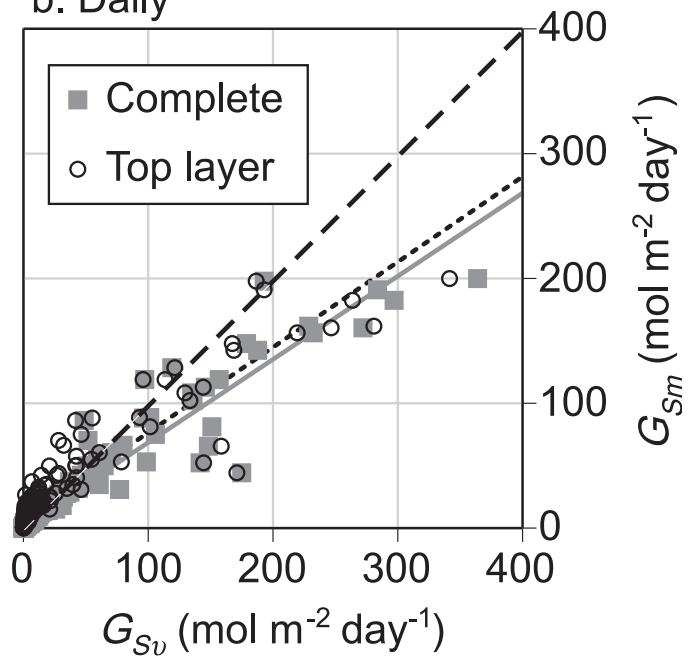

d.

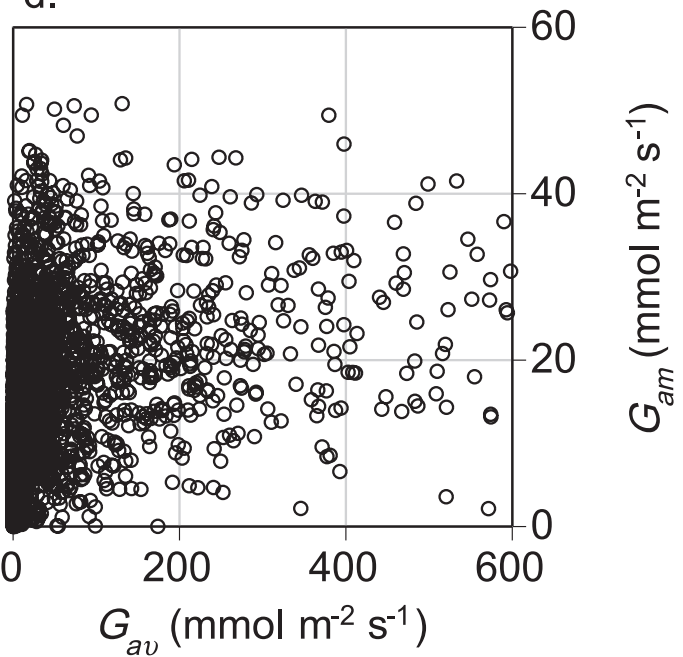

FIG. 3. Comparison of $C_{D}$-based $\left(G_{S m}\right.$ and $\left.G_{a m}\right)$ and $C_{E}$-based $\left(G_{S v}\right.$ and $\left.G_{a v}\right)$ conductances. Comparison of surface conductances $G_{S v}$ vs $G_{S m}$ at (a),(c) 30-min and (b) daily time scales. Dashed line shows 1:1 line. In (b), complete (squares and solid line) and top layer (circles and broken line) are shown. In (c), top layer (filled squares and solid line), full layer (open squares and broken line), and base layer (circles and dash-dotted line) are shown. (d) Aerodynamic conductance to vapor transfer $G_{a v}$ vs momentum transfer $G_{a m}$.

\section{c. Penman-Monteith: Surface and canopy} conductance

The PM equation was inverted to compare $G_{S m}$ to $G_{S v}$. In both cases, $G_{S x}$ includes conductance from soil, understory, and canopy surfaces (Brutsaert 1982). Inversion of the PM equation was computed as

$G_{S x}^{-1}=r_{a x}\left\{\left[\left(\frac{\Delta Q_{A}+\rho_{a} c_{P} D r_{a x}^{-1}}{\lambda \overline{w^{\prime} q^{\prime}}}-\Delta\right) \gamma^{-1}\right]-1\right\}$,

where $Q_{A}$ is the difference between net radiation flux and ground heat flux, $\rho_{a}$ is the density of moist air, $c_{P}$ is the heat capacity of moist air, $D$ is the vapor pressure deficit, $\Delta$ is the slope of the saturation vapor pressure curve against temperature, and $\gamma$ is the psychrometric coefficient. For comparison to physiological measures of conductance $(G)$, units were converted as $G\left(\mathrm{mmol} \mathrm{m}^{-2} \mathrm{~s}^{-1}\right)=\rho_{a}\left(\mathrm{~g} \mathrm{~m}^{-3}\right) G\left(\mathrm{~m} \mathrm{~s}^{-1}\right) / 0.018$ $\left(\mathrm{g} \mathrm{mmol}^{-1}\right)$.

Additionally, FAO56 was applied using $r_{a x}$ to estimate $E_{0 x}$ (Allen et al. 1998; Jensen et al. 1990):

$$
\lambda E_{0 \mathrm{x}}=\frac{\Delta Q_{A}+\rho_{a} c_{P} D r_{a x}^{-1}}{\Delta+\gamma\left[1+\left(G_{C} r_{a x}\right)^{-1}\right]} .
$$


a. Complete model
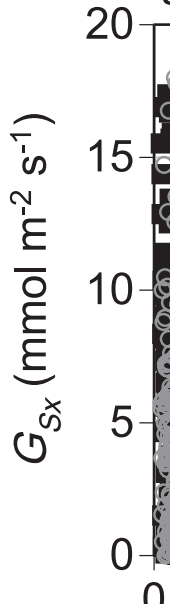

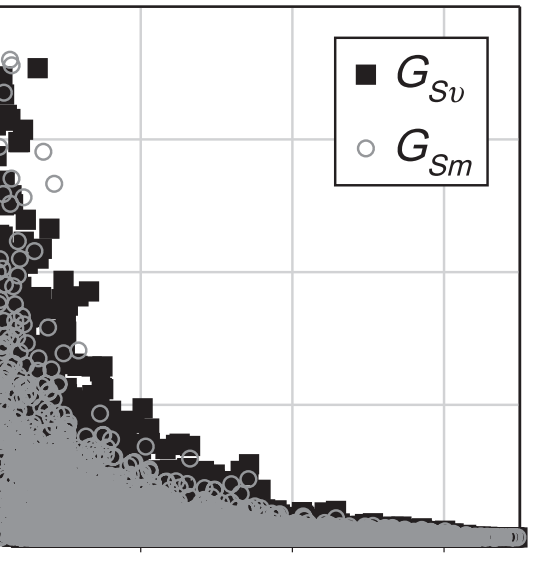

0

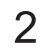

4

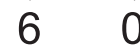

$D(\mathrm{kPa})$

b. Layers

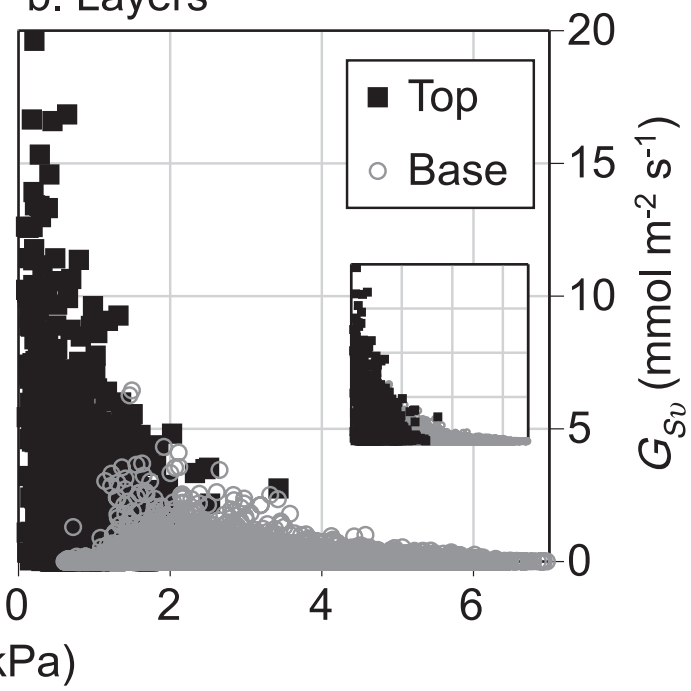

FIG. 4. $G_{S v}$ or $G_{S m}$ as a function of vapor pressure deficit $D$. (a) Complete model $G_{S v}$ (squares) and $G_{S m}$ (circles). (b) Top (squares) and base (circles) layers. The inset is the same as in (b) but with top layer superimposed over base layer.

Canopy conductance $\left(G_{C}\right)$ was estimated in place of $G_{S}$ as a function of leaf resistance $\left(r_{L}\right)$ and leaf area index (LAI): $G_{C}^{-1}=r_{L} /(0.5 \mathrm{LAI})$, in which $r_{L}\left(100 \mathrm{~s} \mathrm{~m}^{-1}\right)$ is the leaf resistance of a well-illuminated grass crop (Allen et al. 1998; Jensen et al. 1990). $E_{0 m}$ is equal to FAO56 for this site's canopy characteristics (i.e., $z_{m}, z_{d}, z_{0}$ ). LAI was interpolated to daily values by applying a spline function to the Moderate Resolution Imaging Spectroradiometer (MODIS) LAI product (Cleverly et al. 2013). Mulga ecosystem $r_{L}$ was determined by inverting the LAI relationship: $r_{L x}=G_{S x}^{-1}(0.5 \mathrm{LAI})$. Additional limitations of soil moisture (below air dry) and small $D$ on evaporation (Choudhury and Monteith 1988) and large $D$ on stomatal function (Ball et al. 1987; Leuning $1995)$ were included in the calculation of $E_{0}$ by using the Water, Atmosphere, Vegetation, Energy and Solutes (WAVES) model, which is a soil-vegetation-atmosphere transfer scheme that employs PM and maintains balance in model complexity among carbon, energy, and water processes (McCallum et al. 2010; Zhang and Dawes 1998).

\section{Results}

Surface soil moisture content had a strong influence over atmospheric moisture gradients across each layer (Figs. 2a-c). Short circuits (i.e., $q_{a}-q_{0}>0$ ) were restricted to periods when soil moisture content was low: $<0.2 \mathrm{~m}^{3} \mathrm{~m}^{-3}$ for the top layer (Fig. $2 \mathrm{a}$ ),$<0.05 \mathrm{~m}^{3} \mathrm{~m}^{-3}$ in the base layer (Fig. 2b), and $<0.12 \mathrm{~m}^{3} \mathrm{~m}^{-3}$ across the full layer (Fig. 2c). Atmospheric humidity gradients were larger and more consistently negative (i.e., $q_{a}<q_{0}$ ) in the base layer than across the top and full layers (Fig. 2 ). The largest gradients in the top and base layers were observed in late spring (5 November) and early summer (22 December), respectively (Fig. 2d), which represent the start of the growing season in the canopy and understory, respectively (Cleverly et al. 2013; Eamus et al. 2013; Ma et al. 2013).

Figure 3 shows the comparison of $G_{S m}$ and $G_{S v}$. Most values were smaller than $15 \mathrm{mmol} \mathrm{m}^{-2} \mathrm{~s}^{-1}$ (Figs. 3a,c). The slope between $G_{S m}$ and $G_{S v}$ was smaller than 1:1, indicating that values of $G_{S m}$ tended to be smaller than $G_{S v}$ (Figs. 3a-c). Notable exceptions in which $G_{S m}>$ $G_{S v}$ occurred at intermediate values of $G_{S v}$ (Figs. 3a,c). Likewise, when integrated over a day, $G_{S m}$ exceeded $G_{S v}$ at low values, which was more pronounced in the top layer alone than when the complete model (Fig. 1) was used for computing $G_{S v}$ (Fig. 3b). When scaled to the same units as $G_{S x}$, aerodynamic conductance to momentum $G_{a m}$ was much smaller than $G_{a v}$ and only marginally larger than $G_{S m}$ (Fig. 3d).

Maximal values of $G_{S v}$ and $G_{S m}$ declined exponentially in response to increasing $D$ (Fig. 4a). At small $(<0.5 \mathrm{kPa})$ and large $(>4 \mathrm{kPa})$ values of $D, G_{S v}$, and $G_{S m}$ were similar (Fig. 4a). However, at intermediate values of $D$, maximal values of $G_{S m}$ were smaller than maximal values of $G_{S v}$ (Fig. 4a). In the top layer, $G_{S v}$ was large and restricted to low and intermediate values of $D$ $(<4 \mathrm{kPa}$; Fig. $4 \mathrm{~b})$. In contrast, in the base layer, which is solvable only during the top-layer short circuit, $G_{S v}$ was generally smaller than $5 \mathrm{mmol} \mathrm{m}{ }^{-2} \mathrm{~s}^{-1}$ and was restricted to intermediate and large values of $D(>0.5 \mathrm{kPa}$; Fig. $4 \mathrm{~b})$. 

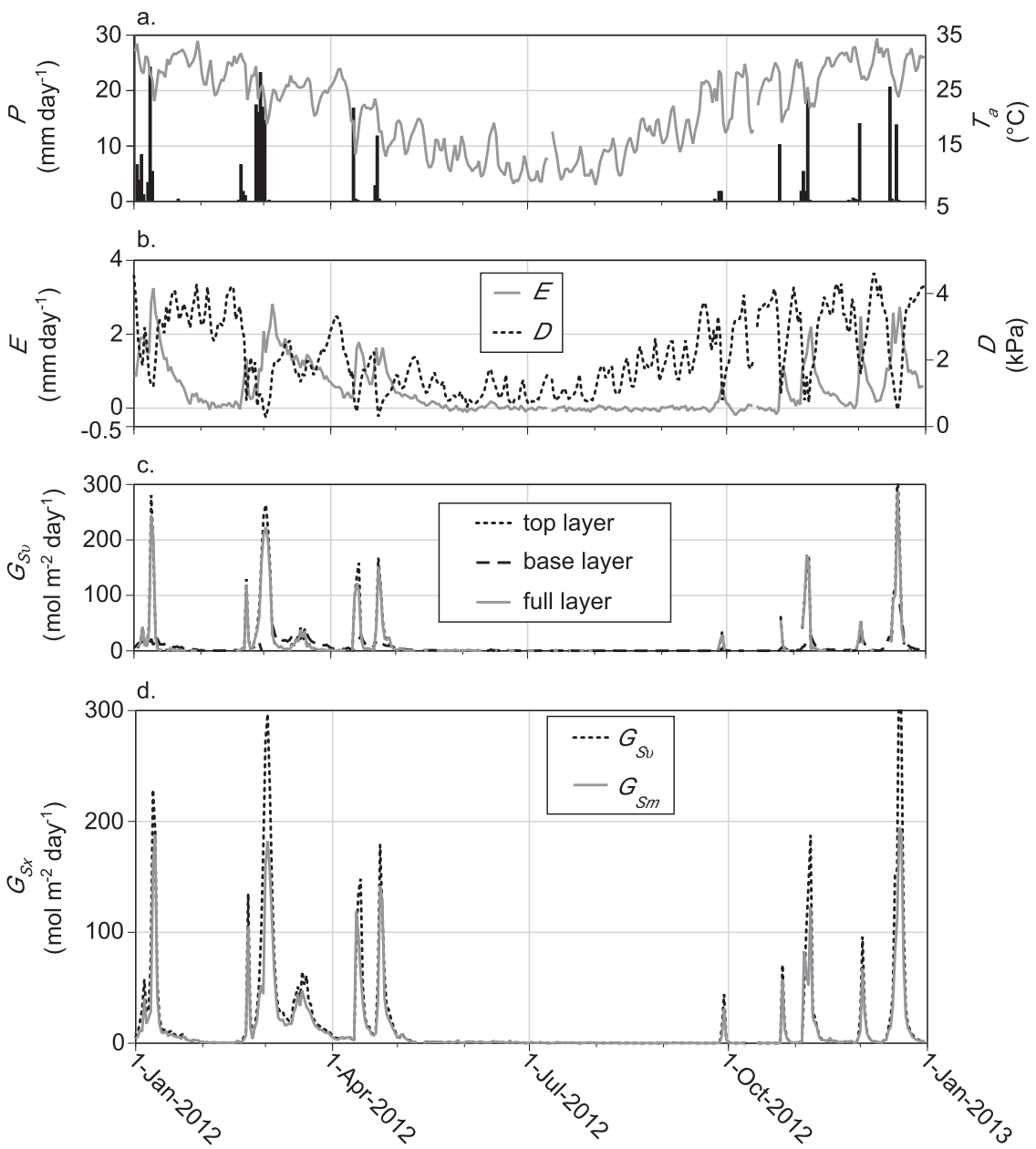

FIG. 5. Daily patterns of (a) $P$ and air temperature at a height of $2 \mathrm{~m}\left(T_{a}\right)$, (b) $E$ and $D$, (c) $G_{S v}$, and (d) $G_{S v}$ and $G_{S m}$.

Figure 5 illustrates daily totals of $P, E, G_{S v}$, and $G_{S m}$ along with average air temperature $\left(T_{a}\right)$ and $D$. Winter (June-August) was particularly dry; thus, $E$ and resultant conductances were negligible (Fig. 5). The $D$ in the winter was often small (minimal daily average $0.6 \mathrm{kPa}$ ) because of low temperature. Rainfall events resulted in further reductions in $D$ (minimal daily average $0.3 \mathrm{kPa}$ ) during any season and at any temperature (Fig. 5b). During periods when $E$ was large, $G_{S v}$ was larger in the top layer than in the full layer (Fig. 5c). The $G_{S v}$ from the base layer was small but prominent in the early autumn (March; Fig. 5c). The complete model showed a stronger conductance response following rainfall than the top layer alone (Fig. 5d); $G_{S m}$ followed the same general pattern as $G_{S v}$, but with smaller values (Fig. 5d).

In general, $r_{L v}$ and $r_{L m}$ were in close agreement except during late summer (Fig. 6a). Consequently, $E_{0 v}$ and
$E_{0 m}$ followed similar patterns (Fig. 6b). A phase shift was observed between EC-based actual $E\left(E_{a}\right)$ and all formulations of $E_{0}$ such that peaks in $E_{a}$ preceded peaks in $E_{0}$ by approximately 2-8 days (Fig. 6b). Divergence between $E_{0 v}$ and $E_{0 m}$ occurred during the dry period of the late summer when $T_{a}$ and $D$ were large (cf. Figs. 5 and 6). Application of WAVES $E_{0}$ resulted in an improved fit to $E_{a}$ (Fig. 6b), especially during the early autumn (Fig. 6b). During summer (e.g., mid-January to mid-February), discrepancy remained between $E_{a}$ and WAVES but was of smaller magnitude than the difference between $E_{a}$ and $E_{0 x}$ (Fig. 6b).

\section{Discussion}

The estimation of $r_{a m}$ as a function of the $C_{D}$ leads to overprediction of $G_{S m}$ at small values of $E$ and to underprediction of $G_{S m}$ at large values of $E$ (Figs. 3b and 

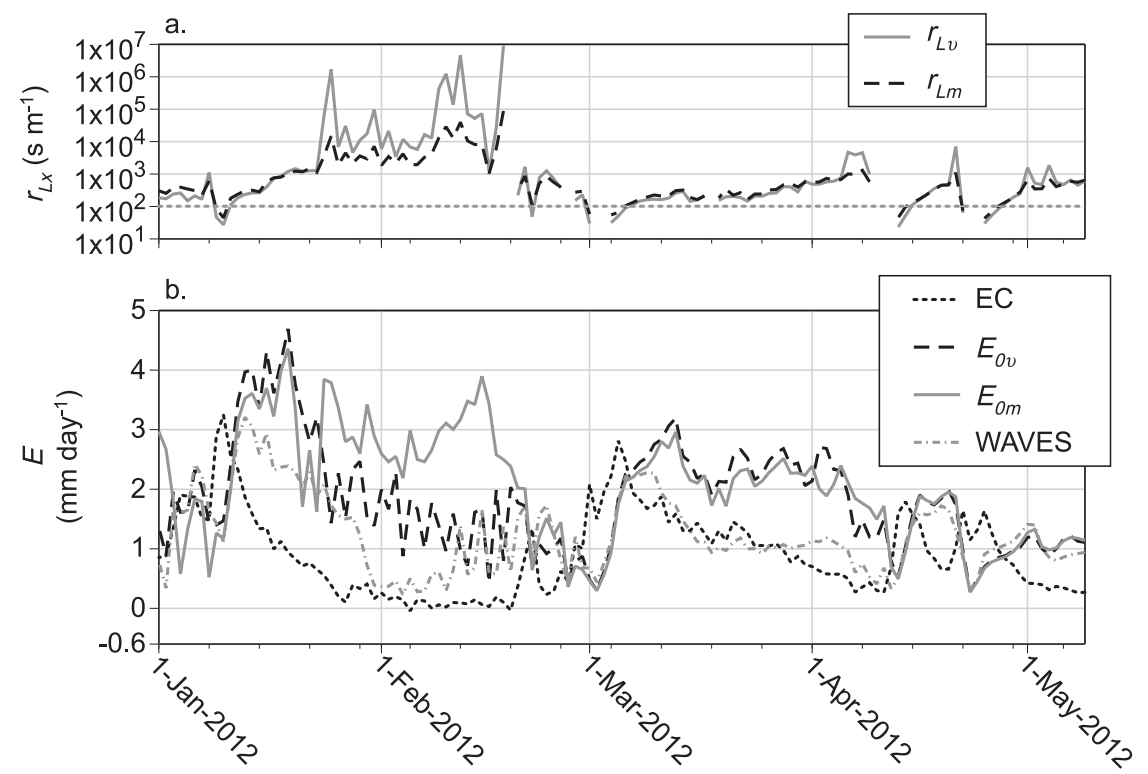

FIG. 6. Daily patterns of leaf resistance $r_{L}$ and $E$. (a) The $r_{L}$ determined from surface resistance inverted with $r_{a v}\left(r_{L v}\right.$, solid line) or $r_{a m}\left(r_{L m}\right.$, dashed line). Grass reference $r_{L}$ shown as a horizontal broken line at $100 \mathrm{~s} \mathrm{~m}^{-1}$ (b) Actual $E$ from EC measurements (broken line) and $E_{0}$ parameterized with $r_{a v}\left(E_{0 v}\right.$, dashed line $), r_{a m}\left(E_{0 m}\right.$, solid line $)$, or from the output of the WAVES model (dash-dotted line).

5b,d,e). Steduto et al. (2003) similarly observed overprediction of $E_{0}$ by FAO56 at low values of $E_{0}$ and underprediction at high values. These patterns of over- and underprediction were observed during the summer when atmospheric gradients in specific humidity $q$ were large (cf. Figs. 2 and 6b), which was the time of year when $r_{a m}$ was expected to underpredict $r_{a v}$. Surface conductance computed from $r_{a v}\left(G_{S v}\right)$ was much smaller than aerodynamic conductance of vapor $G_{a v}$ (Fig. 3) and consequently reduced the influence of errors in estimation of $G_{a v}$ on the determination of $G_{S v}$ and $E_{0}$ (Fig. 3).

To accurately fit $E_{0}$ to prevailing conditions, a large amount of meteorological data is required (Dehbozorgi and Sepaskhah 2012; Tian and Martinez 2012). Failure to account for the influence of atmospheric gradients in $q$ by $C_{D}$ resulted in underestimation of $G_{S m}$ at small to moderate values of vapor pressure deficit $(0.5 \mathrm{kPa}<$ $D<3.5 \mathrm{kPa}$; Fig. 4a). This underestimation occurred because $r_{a m}$ was too large relative to $r_{a v}$, thus reducing the strength of the aerodynamic term $\rho_{a} c_{P} D r_{a x}^{-1}$ [Eqs. (3) and (4)]. Because $E$ is sensitive to small variations in $G_{S m}$ regardless of the $C_{D}$ formulation that is used (Shahrokhnia and Sepaskhah 2012), measurement of atmospheric humidity profiles improved PM estimates of $E_{0}$ by more closely matching the true site-specific aerodynamic resistance (cf. Figs. 2, 5, and 6).

Leaf-level stomatal resistance $r_{L}$ was variable and much larger than for the grass reference (i.e., $100 \mathrm{~s} \mathrm{~m}^{-1}$,
Fig. 6a). A constant $r_{L}$ accounts for neither nonphysiological (Steduto et al. 2003) nor physiological contributions to canopy conductance $G_{C}$ in vegetation that demonstrates large physiological responses to precipitation. The Mulga plants under investigation here are a good example of vegetation that experiences only partial stomatal closure at low water potential $(<-5 \mathrm{MPa})$ and large $D$ (O'Grady et al. 2009). Natural ecosystems are characterized by complex soil and atmospheric moisture gradients that change with soil moisture, growth responses in understory vegetation, and stress responses in the upper canopy (Cleverly et al. 2013).

Mismatch between $E_{a}$ and $E_{0}$ occurred because of 1) the delay between precipitation and vegetation greening, 2) unaccounted soil moisture limitations on $r_{L}$, and 3) seasonal divergence between $r_{a v}$ and $r_{a m}$. The lag of $E_{0}$ behind $E_{a}$ following precipitation was the result of 1 ) the dependence of $E_{0}$ on LAI and 2) heterogeneously rapid drying of the soil surface, which leads to underestimation of $E_{0}$ by WAVES (cf. Fig. 6 and Cleverly et al. 2013). Thus, $E_{0}$ failed to capture the initial pulse of evaporation, which can be particularly important in semiarid areas with intermittent rainfall (Cleverly et al. 2013; Eamus et al. 2013). Application of WAVES improved the fit between $E_{0}$ and $E_{a}$, especially during seasons when $E_{0 v}$ and $E_{0 m}$ were equivalent (Fig. 6). Altogether, accurate prediction of $E_{0}$ was dependent upon 1) characterization of $r_{a v}$ that was responsive to 
atmospheric humidity profiles and 2) identification of leaf physiological and soil moisture (Choi et al. 2012) limitations on $E$ that are not modeled by PM.

Acknowledgments. This work was supported by grants from the Australian Government's Terrestrial Ecosystems Research Network (TERN; www.tern.org.au) and the National Centre for Groundwater Research and Training (NCGRT).

\section{REFERENCES}

Allen, R. G., L. S. Pereira, D. Raes, and M. Smith, 1998: Crop evapotranspiration: Guidelines for computing crop water requirements. FAO Irrigation and Drainage Paper 56, $300 \mathrm{pp}$.

Ball, J. T., I. E. Woodrow, and J. A. Berry, 1987: A model predicting stomatal conductance and its contribution to the control of photosynthesis under different environmental conditions. Progress in Photosynthesis Research, Vol. 4. Kluwer Academic Publishers, 221-224.

Brutsaert, W., 1982: Evaporation into the Atmosphere: Theory, History, and Applications. D. Reidel, 299 pp.

Choi, M., W. P. Kustas, and R. L. Ray, 2012: Evapotranspiration models of different complexity for multiple land cover types. Hydrol. Processes, 26, 2962-2972, doi:10.1002/ hyp. 8346.

Choudhury, B. J., and J. L. Monteith, 1988: A 4-layer model for the heat-budget of homogeneous land surfaces. Quart. J. Roy. Meteor. Soc., 114, 373-398, doi:10.1002/qj.49711448006.

Cleugh, H. A., M. R. Raupach, P. R. Briggs, and P. A. Coppin, 2004: Regional-scale heat and water vapour fluxes in an agricultural landscape: An evaluation of CBL budget methods at OASIS. Bound.-Layer Meteor., 110, 99-137, doi:10.1023/ A:1026096711297.

Cleverly, J., cited 2011: Alice Springs Mulga OzFlux site. OzFlux: Australian and New Zealand Flux Research and Monitoring Network. [Available online at http://ozflux.its.monash. edu.au/ecosystem $/$ pub/viewColDetails.jspx? collection.id = 152\&collection. owner.id $=101 \&$ viewType $=$ anonymous. $]$

— - and Coauthors, 2013: Dynamics of component carbon fluxes in a semi-arid Acacia woodland, central Australia. J. Geophys. Res. Biogeosci., doi:10.1002/jgrg.20101, in press.

Dehbozorgi, F., and A. R. Sepaskhah, 2012: Comparison of artificial neural networks and prediction models for reference evapotranspiration estimation in a semi-arid region. Arch. Agron. Soil Sci., 58, 477-497, doi:10.1080/ 03650340.2010 .530255 .

Eamus, D., and R. Froend, 2006: Groundwater-dependent ecosystems: The where, what and why of GDEs. Aust. J. Bot., 54, 91-96, doi:10.1071/BT06029.

_, J. Cleverly, N. Boulain, N. Grant, R. Faux, and R. VillalobosVega, 2013: Carbon and water fluxes in an arid-zone Acacia savanna woodland: An analyses of seasonal patterns and responses to rainfall events. Agric. For. Meteor., doi:10.1016/ j.agrformet.2013.04.020, in press.

Er-Raki, S., A. Chehbouni, G. Boulet, and D. G. Williams, 2010: Using the dual approach of FAO-56 for partitioning ET into soil and plant components for olive orchards in a semi-arid region. Agric. Water Manage., 97, 1769-1778, doi:10.1016/ j.agwat.2010.06.009.
Hutley, L. B., R. Leuning, J. Beringer, and H. A. Cleugh, 2005: The utility of the eddy covariance techniques as a tool in carbon accounting: Tropical savanna as a case study. Aust. J. Bot., 53, 663-675, doi:10.1071/BT04147.

Isaac, P. R., R. Leuning, J. M. Hacker, H. A. Cleugh, P. A. Coppin, O. T. Denmead, and M. R. Raupach, 2004: Estimation of regional evapotranspiration by combining aircraft and groundbased measurements. Bound.-Layer Meteor., 110, 69-98, doi:10.1023/A:1026054317990.

Jensen, M. E., R. D. Burman, and R. G. Allen, Eds., 1990: Evapotranspiration and Irrigation Water Requirements. American Society of Civil Engineers, 332 pp.

Lemeur, R., and L. Zhang, 1990: Evaluation of three evapotranspiration models in terms of their applicability for an arid region. J. Hydrol., 114, 395-412, doi:10.1016/ 0022-1694(90)90067-8.

Leuning, R., 1995: A critical appraisal of a combined stomatalphotosynthesis model for $\mathrm{C}_{3}$ plants. Plant Cell Environ., 18, 339-355, doi:10.1111/j.1365-3040.1995.tb00370.x.

Ma, X., and Coauthors, 2013: Spatial patterns and temporal dynamics in savanna vegetation phenology across the North Australian Tropical Transect. Remote Sens. Environ., 139, 97-115, doi:10.1016/j.rse.2013.07.030.

McCallum, J. L., R. S. Crosbie, G. R. Walker, and W. R. Dawes, 2010: Impacts of climate change on groundwater: A sensitivity analysis of recharge. Hydrogeol. J., 18, 1625-1638, doi:10.1007/ s10040-010-0624-y.

Monteith, J. L., 1965: Evaporation and the environment. The State and Movement of Water in Living Organisms, Symp. of the Society for Experimental Biology, No. 19, University Press, 205-234.

O'Grady, A. P., P. G. Cook, D. Eamus, A. Duguid, J. D. H. Wischusen, T. Fass, and D. Worldege, 2009: Convergence of tree water use within an arid-zone woodland. Oecologia, 160, 643-655, doi:10.1007/s00442-009-1332-y.

Penman, H. L., 1948: Natural evaporation from open water, bare soil, and grass. Proc. Roy. Soc. London, 193A, 120 145.

Reichstein, M., and Coauthors, 2002: Severe drought effects on ecosystem $\mathrm{CO}_{2}$ and $\mathrm{H}_{2} \mathrm{O}$ fluxes at three Mediterranean evergreen sites: Revision of current hypotheses? Global Change Biol., 8, 999-1017, doi:10.1046/ j.1365-2486.2002.00530.x.

Shahrokhnia, M. H., and A. R. Sepaskhah, 2012: Evaluation of wheat and maize evapotranspiration determination by direct use of the Penman-Monteith equation in a semi-arid region. Arch. Agron. Soil Sci., 58, 1283-1302, doi:10.1080/ 03650340.2011 .584216$.

Sheffield, J., E. F. Wood, and F. Munoz-Arriola, 2010: Long-term regional estimates of evapotranspiration for Mexico based on downscaled ISCCP data. J. Hydrometeor., 11, 253-275, doi:10.1175/2009JHM1176.1.

Steduto, P., M. Todorovic, A. Caliandro, and P. Rubino, 2003: Daily reference evapotranspiration estimates by the PenmanMonteith equation in southern Italy. Constant vs. variable canopy resistance. Theor. Appl. Climatol., 74, 217-225, doi:10.1007/s00704-002-0720-6.

Stull, R. B., 1988: An Introduction to Boundary Layer Meteorology. Kluwer Academic Publishers, 666 pp.

Tabari, H., A. Aeini, P. H. Talaee, and B. S. Some'e, 2012: Spatial distribution and temporal variation of reference evapotranspiration in arid and semi-arid regions of Iran. Hydrol. Processes, 26, 500-512, doi:10.1002/hyp.8146. 
Tian, D., and C. J. Martinez, 2012: Forecasting reference evapotranspiration using retrospective forecast analogs in the southeastern United States. J. Hydrometeor., 13, 1874-1892, doi:10.1175/JHM-D-12-037.1.

Whitley, R., B. Medlyn, M. Zeppel, C. Macinnis-Ng, and D. Eamus, 2009: Comparing the Penman-Monteith equation and a modified Jarvis-Stewart model with an artificial neural network to estimate stand-scale transpiration and canopy conductance. J. Hydrol., 373, 256-266, doi:10.1016/j.jhydrol.2009.04.036.
Wohlfahrt, G., A. Haslwanter, L. Hortnagl, R. L. Jasoni, L. F. Fenstermaker, J. A. Arnone, and A. Hammerle, 2009: On the consequences of the energy imbalance for calculating surface conductance to water vapour. Agric. For. Meteor., 149, 1556-1559, doi:10.1016/j.agrformet.2009.03.015.

Zhang, L., and W. Dawes, Eds., 1998: WAVES: An integrated energy and water balance model. CSIRO Land and Water Tech. Rep. 31/98, 218 pp. [Available online at http://www.clw. csiro.au/products/waves/.] 
